\title{
AUTONOMIA UNIVERSITÁRIA: PRINCÍPIO INERENTE OU CONQUISTA NECESSÁRIA?
}

\author{
AUTONOMÍA UNIVERSITARIA: ¿PRINCIPIO INERENTE \\ O CONQUISTA NECESARIA?
}

\section{UNIVERSITY AUTONOMY: INHERENT PRINCIPLE OR A NECESSARY CONQUEST?}

Lalo Watanabe Minto

Universidade Estadual de Campinas

\begin{abstract}
Resumo $\mathrm{O}$ artigo trata da questão da autonomia universitária à luz das políticas para a educação superior no Brasil. Adotam-se como referências as determinações estruturais que interpõem limites para o exercício dessa autonomia, intensificadas com o neoliberalismo. Argumentamos que as atividades-fim das instituições universitárias são determinadas historicamente, no âmbito dos conflitos de interesses que pautam a luta de classes e suas formas de expressão no ensino superior; portanto, o princípio de autonomia não está isolado desse conjunto de determinações. No período contemporâneo, apesar do princípio legal da autonomia ter atingido seu ponto de maior avanço na Constituição Federal de 1988, também houve mudanças estruturais na educação superior, de modo a alterar as possibilidades concretas de vigência da autonomia universitária. Defendemos, por fim, que a autonomia é uma conquista necessária, não restrita ao princípio formal que a rege, ou eventuais regulamentações, mas uma condição para que a universidade pública possa se transformar, formulando novos projetos e formas de inserção social distintas daquelas que possui na sociedade atual.
\end{abstract}

Palavras-chave: Ensino superior; Universidade; Autonomia universitária.

Abstract The article deals with the question of university autonomy in the light of the policies for Higher Education in Brazil. Structural determinations that place limits on the exercise of this autonomy, intensified with neoliberalism, are adopted as references. We argue that the essential activities of the universities are historically determined within the framework of conflicts of interest that govern class struggle and their forms of expression 
in Higher Education. Therefore, the principle of autonomy is not isolated from this set of determinations. In the contemporary period, although the legal principle of autonomy reached its point of greatest progress in the Federal Constitution of 1988, there were also structural changes in Brazilian Higher education, in order to change the concrete possibilities for the validity of university autonomy. We argue, finally, that autonomy is a necessary achievement, not restricted to the formal principle that governs it, or possible regulations, but a condition for the public university to be able to transform itself, formulating new projects and forms of social insertion different from those it possesses nowadays.

Key-words: Higher EdUCATION; University; University aUtonomy.

RESUMEN El artículo trata de la cuestión de la autonomía universitaria a la luz de las políticas para la educación superior en Brasil. Se adoptan como referencias las determinaciones estructurales que interponen límites para el ejercicio de esa autonomía, intensificadas con el neoliberalismo. Sostenemos que las actividades esenciales de las instituciones universitarias son determinadas históricamente, en el marco de los conflictos de intereses que pautan la lucha de clases y sus formas de expresión en la enseñanza superior; por lo tanto, el principio de autonomía no está aislado de ese conjunto de determinaciones. En el período contemporáneo, a pesar del principio legal de la autonomía haber alcanzado su punto de mayor avance en la Constitución Federal de 1988, también hubo cambios estructurales en la educación superior, de modo a alterar las posibilidades concretas de vigencia de la autonomía universitaria. Defendemos, por fin, que la autonomía es una conquista necesaria, no restringida al principio formal que la rige, o eventuales regulaciones, sino una condición para que la universidad pública pueda transformarse, formulando nuevos proyectos y formas de inserción social distintas de aquellas que posee en la sociedad actual.

Palabras Clave: Enseñanza superior; Universidad; Autonomía universitaria.

\section{UM PONTO DE PARTIDA}

A despeito da variedade de significados produzidos sobre a autonomia ao longo do tempo, parece consenso que essa é uma questão entendida como crucial para a universidade. Formas distintas de conceber e projetar as funções dessas instituições, em geral, redundam em concepções igualmente distintas de autonomia. No Brasil, apesar da educação superior ter uma história ainda relativamente curta, essa discussão é anterior à própria existência das universidades.

Estudos acadêmicos, organizações sindicais e entidades científicas do campo educacional têm alertado, sobretudo nas últimas três décadas, para as constantes investidas das políticas educacionais contra o princípio da autonomia universitária no país. As ameaças às quais se referem são reais e os embates contrários a ela fazem parte da vida das instituições. Nesse campo, porém, é comum vermos dois tipos de tratamento dados ao tema: um, que assume a autonomia como característica da universidade desde suas origens enquanto instituição e, portanto, algo que nos chegou como uma tradição ou um ideal a ser realizado. 
No período moderno, a universidade de Humboldt seria uma dessas referências principais, inaugurando o "padrão" da autonomia buscada até hoje. Amiúde, afirma-se que não haveria universidade sem autonomia, do que se poderia deduzir que se há universidade, há autonomia em algum grau. Essa é uma identidade frágil, porque torna o significado da autonomia demasiadamente abstrato e relativo, de forma que as determinantes históricas da existência e do funcionamento das instituições fiquem secundarizadas. O outro tipo de abordagem toma como ponto de partida a legislação e sua aplicação. No caso brasileiro, teria se iniciado com a Reforma Rivadávia Corrêa, de 1911, e chegado à sua forma mais abrangente na Constituição Federal de $1988 .{ }^{1}$

Isoladamente, nem uma nem outra das abordagens parecem-nos suficiente. Mas é lícito reconhecer que elas estabelecem marcos importantes, sobre os quais os posicionamentos políticos em torno da autonomia costumam se alicerçar. Estudos como os de Charle e Verger (1996) e Fétizon (2012), ademais, já constataram que a autonomia vem sendo uma condição buscada pelas universidades desde suas origens medievais (face às interferências eclesiásticas ou monárquicas, por exemplo), mas disso não decorre que os sentidos da autonomia permaneçam imutáveis. Devemos, então, nos perguntar, retomando o problema de fundo: há/houve uma perda efetiva da autonomia da universidade brasileira ou estamos tratando de um processo permanente de negociação e conflito, no qual se estabelecem os limites possíveis para um exercício mais autônomo das funções específicas dessas instituições?

O ponto de partida que defendemos, nesse estudo, é o de que só é possível analisar a autonomia universitária no contexto social e histórico no qual estão inseridas as universidades. Nesse sentido, não tomamos como um dado as idealizações que elevam a autonomia à condição de característica essencial da universidade, em referência a uma "concepção originária" da instituição que seria o berço da liberdade, da autonomia de pensamento, da universalidade do conhecimento. ${ }^{2}$ Igualmente, as buscas por uma autonomia perdida, ou, ainda, aquelas que tomam como ponto de partida o sentido etimológico da palavra, não nos parecem produtivas. ${ }^{3}$ A máxima de que sem autonomia não haveria universidade não pode servir para ocultar o fato de que as universidades não só vêm existindo e se mantendo em períodos de profunda escassez de autonomia, como compactuando com projetos, ideias e práticas que inviabilizam qualquer sentido concreto de autodeterminação. ${ }^{4}$

Para um balanço sintético da história desse princípio, ver Fávero (1997).

2 Bento (2016, p. 139-143), por exemplo, entende que o Processo de Bolonha representa uma "traição" ao ideal iluminista e humanista da universidade moderna, fundada por von Humboldt em Berlim.

3 O objetivo, aqui, não é menosprezar as intepretações que vêm conformando um campo de estudos e debates a respeito do ensino superior, e sim ampliar o campo de reflexão sobre a autonomia e a universidade, evitando os riscos que uma análise pautada na tradição, nas "origens" ou no sentido etimológico, poderiam trazer. A respeito disso, recomendamos as anotações deixadas por Marc Bloch (2001, p. 58), historiador da primeira geração da Escola dos Annales, acerca do que denominou de "ídolo das origens".

4 Sobre isso, ver também Leher (2003, p. 8). 


\section{A Universidade Na SOCIEDAde De ClASSES: PODE HAVER AUTONOMIA?}

Instituições que surgiram em experiências distintas da nossa, mas que aqui se instalaram no bojo do desenvolvimento histórico do capitalismo e de sua lógica de produção, foram obedecendo a uma dinâmica contraditória que uniu tradições, modos de ser previamente concebidos e, sobretudo, adequação às condições efetivamente existentes, possíveis e necessárias em nossa formação social. ${ }^{5}$ Para uma abordagem introdutória desse assunto, optamos por retomar alguns autores clássicos e as reflexões que fizeram sobre a universidade.

Em meados do século XX, Anísio Teixeira lamentava a ausência da universidade no país. Sua formulação continha um tom idealista, mas as críticas que fez sobre a escola superior aqui existente ajudam a compor um quadro realista do que foi a construção desse nível de ensino e suas consequências para a cultura nacional:

Ficam [...] perfeitamente claros os motivos do que costumamos chamar a alienação da cultura nacional e os equívocos relativos à própria cultura geral de nossa época, como a hostilidade à universidade e a repentina ênfase positivista dos começos da República, com idêntica hostilidade à universidade. Não só não criamos as fontes que iriam gerar a cultura nacional - a universidade com estudos superiores da cultura humanística e histórica e, depois, com a cultura científica (não-profissional) - como éramos contra a existência dessas fontes, esperando ou supondo que a cultura profissional de escolas de medicina, de direito e de engenharia nos daria, não se sabe como, uma cultura nacional (TEIXEIRA, 2005, p. 183-184).

A provocação dirigida às escolas superiores questionava a sua capacidade de cumprir tarefas que as universidades haviam cumprido no desenvolvimento nacional de outros países. De onde a conclusão de que tais escolas, por serem consumidoras da cultura europeia, fortaleciam a "alienação cultural", expressando a ausência dos elementos necessários para uma efetiva autonomia (TEIXEIRA, 2005, p. 184).

Darcy Ribeiro (1991, p. 87-88) tratou desse assunto em A universidade necessária. Para ele, toda e qualquer forma de pensamento que caracterizava a universidade como instituição isolada ou acima das relações de poder e dos antagonismos sociais invocava posicionamento ideológico conservador frente aos conflitos político-econômicos, sociais e culturais de um dado tempo histórico. Essa crítica visava mostrar que as retóricas que alimentavam uma imagem pretensamente pura sobre a instituição universitária e suas finalidades, acabavam por exercer a função de ocultar a universidade realmente existente.

Florestan Fernandes elaborou uma visão mais problematizada da universidade brasileira, e uma de suas referências foi justamente uma crítica ao pensamento de Ribeiro:

O que parece, à primeira vista, um diagnóstico pessimista e amargo, é, no fundo, uma mensagem de fé nos homens, nas instituições e na sua história: a uni-

5 Em Minto (2014) tivemos o objetivo de deixar uma contribuição nesse sentido, também. 
versidade do terceiro mundo fará a revolução cultural do terceiro mundo. $\mathrm{O}$ subdesenvolvimento gera o seu contrário; no caso, a universidade subdesenvolvida gera a universidade autônoma, liberadora e revolucionária que a história exige (FERNANDES, 1975, p. 266).

O alerta de Fernandes nos parece atual e relevante, podendo ser assim resumido: não se pode analisar a universidade brasileira sem estar amparado por uma leitura abrangente da realidade social e educacional do país. Embora isso estivesse presente na obra de Ribeiro, Fernandes entendeu que o autor não escapou do terreno perigoso da "irradiação" de certas construções intelectuais para o campo da realidade histórica, de onde a crença exacerbada no papel a ser cumprido pela universidade brasileira. Dizia, então, que a universidade, em certos contextos, pouco pode, seja como "força reformista", seja como "força revolucionária":

O campo de forças que predomina na universidade é o mesmo que predomina na sociedade global - ultra-reacionário e contra-revolucionário, mesmo em confronto com os requisitos legais da democracia representativa (FERNANDES, 1975, p. 267-268).

De Maurício Tragtenberg adveio outra importante síntese:

\begin{abstract}
A universidade não é uma instituição neutra, é uma instituição de classe onde as contradições de classe aparecem. Para obscurecer esses fatores ela desenvolve uma ideologia, um saber neutro, científico, quer dizer, a neutralidade cultural e o mito de um saber "objetivo" acima das contradições sociais. Isso se acirrou a partir de 1964, quando a Universidade foi praticamente apartada da realidade, se encastelou. Nesse momento surgiu a figura do intelectual burocrata, do funcionário intelectual, que mais reproduz do que produz conhecimento próprio (TRAGTENBERG, 2011, p. 215).
\end{abstract}

Portanto, se as possibilidades de autonomia das universidades nas sociedades capitalistas são limitadas, mesmo nos países centrais, em países periféricos como o Brasil esses limites são ainda mais estreitos. Mas o que nos interessa é tratar disso no terreno histórico em que se pode compreender a problemática da autonomia universitária no Brasil contemporâneo. Essa tarefa torna obrigatória uma análise das dinâmicas particulares que o modo de produção capitalista, nas condições do desenvolvimento desigual e combinado, impõe para a relação da universidade com a sociedade (formas de organização, formação de quadros e força de trabalho especializada, produção de conhecimento e tecnologia etc.). Em tais condições, a autonomia da universidade é um campo de disputas e tensões permanentemente repostas.

Por tudo isso, se as considerações de Fernandes sobre a universidade, escritas durante a fase mais difícil da ditadura civil-militar, em fins dos anos 1960, podem soar demasiadamente duras, devemos nos perguntar: terão perdido sua significação? 


\section{A autonomia na legislação Vigente: Garantias ou limites?}

Sem desconsiderar o fato de que a legislação é uma das referências a demarcar o "lugar" ocupado pela instituição universitária, podemos nos perguntar: a legislação institui as condições para o exercício da autonomia ou, ao contrário, ela regula e controla os limites desse exercício à medida que as instituições a tornam uma demanda objetiva?

A autonomia já estava prevista em leis anteriores. Nas Diretrizes e Bases da Educação de 1961, a primeira LDB (Lei 4.024/1961), o artigo 80 consagrara a autonomia ("didática, administrativa, financeira e disciplinar") como prerrogativa das universidades, ao passo que seu artigo 84 concedia ao então Conselho Federal de Educação a prerrogativa de suspendê-la por tempo determinado e mediante "inquérito administrativo". Antes disso, no Estatuto das Universidades Brasileiras (Decreto n. 19.851/1931), essa referência apareceu pela primeira vez no artigo $9^{\circ}$. que especificava a autonomia universitária como "didática, administrativa e disciplinar". Ainda mais atrás, a Lei Orgânica do Ensino Superior e do Fundamental da República, baixada pelo Decreto n. 8.659, de 5/4/1911, instituíra o primeiro marco legal do princípio de autonomia no ensino superior, ainda que não tenha tido vigência duradoura (RANIERI, 1994, p. 62).

Na legislação vigente, a autonomia das universidades é uma prerrogativa prevista na Constituição Federal de 1988, Artigo 207: "As universidades gozam de autonomia didático-científica, administrativa e de gestão financeira e patrimonial, e obedecerão ao princípio de indissociabilidade entre ensino, pesquisa e extensão". A extensão dessa prerrogativa às instituições de pesquisa científica e tecnológica foi incluída pela Emenda Constitucional $n$. 11, de 1996, tornando-se o $\S 2^{\circ}$. do Artigo 207: "O disposto neste artigo aplica-se às instituições de pesquisa científica e tecnológica".

Mas o que significa autonomia, do ponto de vista jurídico e do direito público? $\mathrm{Na}$ opinião da mesma autora já citada, uma jurista e estudiosa do ensino superior:

$\mathrm{Na}$ área do direito público, os doutrinadores contemporâneos são unânimes em definir autonomia como poder de autonormação exercitável nos limites impostos pelo ordenamento superior que the deu origem (RANIERI, 1994, p. 223).

A autora completa, se referindo ainda ao direito público:

[...] a autolimitação da lei consiste em abstenção proposital do legislador (a ser disciplinada pelos entes públicos mediante o exercício de sua autonomia), ou em edição de normas dispositivas que o próprio legislador consente serem substituídas por disposições autônomas (RANIERI, 1994, p. 23).

Por fim, apresenta aquilo que vem sendo repetido por muitos estudos, no tratamento da autonomia universitária:

Autonomia não significa independência nem soberania. Seu exercício, embora pleno, restringe-se a esferas específicas previamente delimitadas pelo ente maior, dentro das quais e para as quais são produzidas pelo ente autônomo normas próprias e integrantes do sistema político global (RANIERI, 1994, p. 27). 
É interessante notar que a contradição indicada no item anterior pode ser vista, também, na forma como se define a concepção jurídica de autonomia: "limitação que a lei impõe a si mesma" (RANIERI, 1994, p. 25). Chama-nos a atenção, também, o fato de que essa obviedade jurídica (o direito burguês jamais admitiria um poder normatizador que subvertesse o próprio ordenamento que o instituiu) seja mobilizada para tratar do assunto autonomia universitária. Isso revela que, por mais que se possa debater o aspecto jurídico, seu alcance e seus limites, toda e qualquer proposição que envolva o funcionamento da universidade e suas atividades-fim, possui uma dimensão política que, no limite, é a que define a norma.

Nesse sentido, a autonomia da universidade não é apenas uma limitação que a Constituição impôs a essa instituição, que deve torná-la operacional no interior do ordenamento jurídico vigente. Ela é mais que isso: o produto de um antagonismo de forças que, antes mesmo do princípio ter sido instituído pela primeira vez, já estava em vigência. Um exemplo citado por Fávero $(1997$, p. 9) nos ajuda a compreender isso. A autora mostra que, além de ter sido tratada legalmente antes de se instituírem as primeiras universidades no Brasil, a temática da autonomia foi levantada "em resposta a um movimento de contenção do crescimento das inscrições nas faculdades". Ou seja, desde o nascedouro, a forma jurídica da autonomia é produto de interesses conflitantes, visando estabelecer controles sobre as instituições de ensino, neste caso, notadamente como forma de obstaculizar o acesso de certas camadas àquele ensino.

O princípio constitucional da autonomia não tem o poder de instituir uma existência efetivamente autônoma para as universidades, pois suas atividades-fim, suas formas de realização e os interesses dos sujeitos que nela interferem, não se encontram isolados do conjunto das relações sociais. Poderia se dizer, ao contrário, que a função do princípio constitucional é antes estabelecer um limite para as pretensões de autonomia que as universidades possam ter; ou, dizendo de outra forma: a autonomia legal não institui, a priori, uma forma de relação da universidade com a sociedade, mas opera sobre relações concretas, buscando controlá-las. ${ }^{6}$ Entre elas, a produção e a apropriação privada de conhecimentos científicos e tecnológicos pelas corporações, a formação de força de trabalho para o mercado, entre outras atividades estratégicas realizadas pelas universidades.

Isso não implica que, no tocante à legislação, os limites impostos à autonomia também não se diferenciem: ora são mais abrangentes (como no texto original da CF 1988), ora são mais restritivos (como no caso da Reforma do Estado dos anos 1990). Formalmente, os avanços de 1988 são inegáveis: o princípio da autonomia adquiriu contornos mais amplos, pois estava associado a um conjunto de outros princípios como a gestão democrática, a indissociabilidade ensino-pesquisa-extensão, a vinculação de recursos públicos para a educação, a gratuidade do ensino público em estabelecimentos oficiais, para citar apenas os mais diretamente ligados ao ensino superior. Apoiou-se, portanto, em garantias formais que indicavam um direcionamento do Estado brasileiro a um caráter público mais amplo, via políticas sociais.

6 A inspiração para tratar desse assunto vem de uma apropriação da Teoria geral do direito e marxismo, de Evgeny Pachukanis (1988), autor cuja obra ainda é pouco conhecida no campo da pesquisa educacional brasileira. 
Nos anos de 1990, período das reformas neoliberais, as reflexões sobre a autonomia universitária, de modo diferente do sentido contestador e de busca pela independência política e ideológica dos anos de luta contra a ditadura, se tornaram campo mais explícito de disputa. Projetos antagônicos de universidade, de sociedade e de educação, passaram a se reportar a temas comuns e, assim, as políticas educacionais que versavam sobre a educação superior e, de modo específico, acerca da autonomia universitária, passaram a ser campo privilegiado de disputa e palco para a reiteração de valores conservadores. Quebrou-se o aparente consenso que havia se formado nos anos anteriores (MANCEBO, 1998, p. 51).

Para Chaú (2001, p. 196-197), é nesse processo que ocorre uma "metamorfose da universidade pública brasileira em organização", expressão do espraiamento da lógica do capital para as suas atividades, tornando-as entidades administradas "cujo sucesso e cuja eficácia se medem em termos da gestão de recursos e estratégicas de desempenho":

\begin{abstract}
De fato, embora o Artigo 207 pareça contemplar a antiga ideia de autonomia universitária, a LDB entende por autonomia simplesmente a gestão eficaz de receitas e despesas, de acordo com contratos de gestão assinados pelas universidades com o Estado. Numa palavra, a autonomia organizacional se reduz ao gerenciamento empresarial da instituição para que cumpra metas, objetivos e indicadores definidos pelo Estado e tenha independência para fazer outros contratos com empresas privadas (CHAUÍ, 2001, p. 204).
\end{abstract}

Com as reflexões feitas até aqui, queremos indicar que a defesa e as lutas por uma universidade autônoma, portanto, ultrapassam em muito a mera implementação do princípio legal da autonomia. Limitá-las a esse objetivo é atuar no terreno do status quo, apenas se valendo de suas regras instituídas (ora alargadas, ora restritivas). A própria noção de que a lei poderia definir o que é a autonomia já é, por si só, uma limitação. E, por mais que se possa recorrer ao argumento jurídico que afirma ser o princípio instituído pelo Artigo 207 de "mera aplicação" (isto é, que produz efeitos imediatos, não precisando, necessariamente, de regulamentação); e que, se tornaria "inconstitucional qualquer lei inferior que disponha sobre a extensão, o sentido ou conteúdo da autonomia das universidades" (RANIERI, 1994, p. 107), ${ }^{7}$ o efetivo significado adquirido pelas atividades-fim dessas instituições não será definido pelo princípio (ou "causa primária") constitucional, que é genérica. Nem por sua eventual regulamentação. O que a define é o efetivo modo de inserção social, político e econômico das instituições universitárias, uma relação que não está circunscrita ao campo educacional, sendo dependente, ainda, das relações entre o Estado e a sociedade brasileira, bem como, destas com o conjunto das demais nações.

Essas considerações nos encaminham a um segundo conjunto de indagações: estaríamos hoje diante de um desses momentos históricos em que, mesmo nas condições contraditórias da sociedade capitalista, é possível alcançar níveis de autonomia mais elevados e significativos em instituições como as universidades?

Para Ranieri (1994, p. 107), ademais, poderia se falar que a autonomia é "conteúdo pétreo" que a Constituição garantiu às universidades. 


\title{
QUAL AUTONOMia É POSSÍVEl NA ATUAL CONJUNTURA?
}

Pelo menos desde as reformas de 1968, as classes e frações de classes dominantes no Brasil vêm combatendo, de modo intenso e sistemático, toda e qualquer forma de educação superior que possa ter um papel ativo e inovador na construção de um capitalismo mais autônomo no Brasil. Nos projetos dominantes dos governos brasileiros, de lá para cá, a educação superior tem sido organizada para funcionar na base do mínimo esforço. Para Leher (2010, p. 36), esse é um processo de reorientação da educação superior brasileira, em diferentes dimensões. Uma delas é a da institucionalização e ampliação da pós-graduação, o que foi estratégico para a produção de conhecimentos necessários ao desenvolvimento do capitalismo nas bases da dependência. Afirma o autor:

\begin{abstract}
Em um contexto ainda pouco estudado, a pós-graduação brasileira (e também de outros países da região) foi instaurada com o apoio do aparato de fomento científico e tecnológico reorganizado em suas funções e composição pela ditadura empresarial-militar: não havia nenhuma dúvida de que o apoio governamental à C\&T nada tinha de emancipatório. De todas as formas, examinando retrospectivamente o período, é possível constatar que parte dos fundos para a pesquisa básica não foi exclusivamente outorgada ao mercado e que a preocupação tecnológica em áreas sensíveis - como energia, telecomunicações, engenharias, saúde, agricultura e pecuária - formava parte do esforço de qualificação das empresas estatais, de centros públicos de pesquisa e de empresas que desenvolviam etapas das cadeias produtivas com certo grau de complexidade. Foi nesses interstícios que se produziu uma ciência e uma tecnologia não diretamente operacionais ao modelo em curso, impulsionando uma pós-graduação contém em sua história, essas contradições [...] (LEHER, 2010, p. 37). ${ }^{8}$
\end{abstract}

Nesses moldes, com o II Plano Nacional de Desenvolvimento (PND) houve um "boom na pesquisa científica" brasileira (LEHER, 2010, p. 38-39), porém, não no sentido de uma produção autônoma, que incrementa as condições de emancipação científico-cultural do país; tratou-se, ao contrário, de uma intensificação da alienação cultural da universidade brasileira. Por outra parte, dimensões como a formação de mão de obra especializada para certos nichos, se manteve como tarefa prioritária das Instituições de Ensino Superior (IES) ditas "de excelência", quase todas estatais; e o atendimento à parte da demanda social por acesso ao nível superior, foi relegada ao setor privado, via generosos estímulos governamentais.

A educação superior que tem se viabilizado no Brasil do pós-ditadura segue o figurino das diretrizes de organismos como o Banco Mundial, expresso em denominações como pós-secundária e terciária (BANCO MUNDIAL, 1995). É uma educação "minimalista" (LEHER, 2010, p. 68-69), reformada sob medida para atender aos interesses do capital em países periféricos. Nessa condição, mesmo sem ter usufruído, efetivamente, de uma posição autônoma (sobretudo quando entendida como vinculação às demandas sociais das maiorias e da classe trabalhadora), a universidade construída no país precisou ser dura-

8 Tradução livre do original em espanhol. 
mente combatida. Sua base era a de uma vinculação particular e tardia ao desenvolvimento econômico em bases nacionais. Conforme a linguagem e os interesses desse projeto reformista, o "modelo de universidade" (equivocadamente indicado como "único" por muitos de seus críticos), "excessivamente caro" e "ineficiente", que teria se esgotado. Estamos falando de um processo que ganhou contornos mais definidos durante as reformas da Ditadura Civil-Militar e se intensificou com o neoliberalismo. Nos países periféricos, portanto, a heteronomia das instituições que produzem ciência e tecnologia não é resultado disso, mas antes um pressuposto. ${ }^{9}$

No período contemporâneo, não foi por outra razão que a reconstrução da heteronomia da educação superior teve como um de seus centros irradiadores justamente a pós-graduação. E a política que caracteriza de forma mais abrangente esse processo, ainda hoje, é a da chamada internacionalização, que funciona como balizadora de uma nova divisão internacional das IES. O princípio da autonomia não foi abandonado formalmente, mas ressignificado conforme os interesses hegemônicos na sociedade brasileira de fins do século XX e início do XXI. Nesse sentido, ter autonomia passou a ser sinônimo de gestão institucional, especialmente a financeira, quando se mede a competência (para captar recursos, reduzindo a dependência do fundo público) e a eficiência (redução de custos, com uso intensivo de tecnologias e estratégias típicas do mundo empresarial), de formação de profissionais para atender às demandas do mercado e setor produtivo; realização de pesquisas e outras atividades (como prestação de serviços - cursos, consultorias, parcerias, aluguel da infraestrutura etc.) ao sabor da lógica privado-mercantil. Parafraseando Chaú, poderíamos chamar de uma autonomia administrada. ${ }^{10}$

Face aos sucessivos cortes financeiros que vêm sendo realizados, desde 2015, num movimento combinado com a elaboração apressada dos projetos que redundaram no congelamento dos gastos sociais imposto pela Emenda Constitucional n. 95/2016, a situação se tornou ainda mais restritiva. São cortes que afetam diretamente a educação superior e um modo de avaliar esse problema é observando a própria política educacional recente e as metas aprovadas pelo PNE (2014-2024). Com base na análise da evolução recente dos recursos financeiros associados ao governo brasileiro, Amaral concluiu que:

[...] a análise da execução orçamentária do Poder Executivo no período 19952016 e do orçamento aprovado na LOA de 2017 nos permite afirmar que o cumprimento das metas contidas no PNE (2014-2024) no contexto da EC 95,

9 Isso não quer dizer que as universidades dos países centrais sejam efetivamente autônomas. O que se está afirmando é que o espaço para a autonomia vai se estreitando em toda a educação superior global, mas seus efeitos atingem distintamente as instituições de diferentes países. Altbach indica que, apesar da complexidade que caracteriza a educação superior "internacionalizada", a predominância das instituições dos países centrais ainda é inquestionável. Os motivos apontados pelo autor, no que se refere ao modo de entendimento da educação superior, diferem daqueles que adotamos neste estudo, contudo uma das suas conclusões deve ser aqui apresentada: "Virtually all Third World nations will remain linked to the technological networks dominated by the industrialized West" (ALTBACH, 2016, p. 167). Essas nações podem, no máximo, completa o autor, constituir sistemas e instituições de pesquisa em certos nichos (limited research capability).

10 Bianchetti, Valle e Pereira (2015) falam em "autonomia regulada" (p. 47-53). 
que perdurará até o ano de 2036, abarcando também o próximo PNE decenal, é uma tarefa praticamente impossível, e pode-se afirmar que a EC 95 determinou a "morte" do PNE [...] (AMARAL, 2017, p. 24).

A restrição financeira não é a única a fazer escassear a autonomia. Porém, não resta dúvida que as dificuldades ora impostas às universidades brasileiras expressam muito mais do que apenas uma crise de "modelo", sendo esta apenas a forma ideológica como seus adversários desqualificam toda e qualquer demanda por financiamento, condição básica para qualquer tipo de autonomia. Ao nosso ver, essa política revela outra forma de inserção social das IES, na qual a relação com o desenvolvimento das forças produtivas se desloca para um novo eixo estratégico. Esse é um processo cada vez mais global, com dois âmbitos principais: de um lado, a comercialização internacional do serviço educacional de nível superior; de outro, a crescente padronização das políticas educacional (envolvendo a formação, os currículos e as formas de gestão institucional e do trabalho docente).

\section{INTERNACIONALIZAÇÃO E INOVAÇÃO: AGENTES DA HETERONOMIA}

Há hoje um campo definido de objetivos hegemônicos, entre os quais está o de fazer que as universidades se especializem em produzir conhecimentos e tecnologia (sobretudo na sua versão "inovação") necessários para a adequação do país às forças dominantes no capitalismo global. É um campo de interesses que, a despeito de sua ambiguidade e contradições, projeta a universidade de forma inédita na alçada dos grandes interesses do capital. Daí o seu caráter "universal", pois aparentemente desprovido de fronteiras, como se fosse a realização do ideal da universidade dos tempos medievais. No léxico que preside essas tendências, o termo que se destaca é internacionalização.

Ouriques (2011) chama essa lógica de produção de conhecimento que extrapola as fronteiras institucionais dos países de "sistema mundial de produção de conhecimento", destacando as formas desiguais de inserção das nações e, particularmente, a condição subordinada e periférica ocupada por países como o Brasil.

\footnotetext{
As revistas indexadas nas bases de dados anteriormente mencionadas ${ }^{11}$ são o meio pelo qual a inteligência dos países periféricos é exibida e gratuitamente disponibilizada para as potências capitalistas para que elas, a partir da relação Estado-empresa-universidade, desenvolvam o controle do conhecimento pelo sistema de patentes (OURIQUES, 2011, p. 81).
}

Trata-se de uma organização estabelecida em nível mundial, mas, evidentemente, não disponibilizada igualmente para todos os países, haja vista que, além do domínio e controle das patentes, impõe-se a capacidade de aplicação tecnológica desses conhecimentos, hegemonizada pelas grandes corporações. Como já afirmamos em estudo anterior, o itinerário da internacionalização da educação superior percorre os caminhos pavimentados:

${ }_{11} \mathrm{O}$ autor se refere às bases ISI (Institute for Scientific Information) e Scopus. 
[...] por acordos internacionais que visam criar um "espaço mundial" para áreas ainda não dominadas pela lógica da acumulação de capital. Seus marcos fundamentais foram a criação da Organização Mundial do Comércio (em 1995, substituindo o GATT) e a definição do Acordo Geral de Comércio e Serviços (AGCS ou GATS, na sigla em inglês), como resultado da Rodada Uruguai do GATT (1986-1994). (Cf. LEHER, 2010, p. 54). Com o GATS em vigor desde 1995, as negociações sobre a educação superior, um dos "serviços" de maior interesse a serem negociados, se aceleraram a partir da Rodada Doha (2001). Naquela ocasião, três países foram os principais defensores da plena liberalização do comércio global da educação superior como serviço: EUA, Austrália e Nova Zelândia. Segundo García-Guadilla (2002, p. 4), o "GATS funciona como uma agenda" com base na qual, a cada rodada de negociações, se gera "maior liberalização, cobrindo mais setores e eliminando maiores restrições" (MINTO, 2014, p. 347).

No relatório para a UNESCO, preparado pela Comissão Internacional sobre Educação para o Século XXI entre 1993 e 1996, conhecido como "Relatório Delors", também se preconizava a cooperação internacional como uma função essencial das universidades. Basicamente, indicava-se que essa cooperação seria basilar para produzir a "geminação de instituições de pesquisa de países industrializados com instituições homólogas de países em desenvolvimento", "parcerias de pesquisa" entre universidades e setor econômico, bem como, a "livre circulação de pessoas e a partilha de conhecimentos" (DELORS et al., 2001, p. 145-146). Cooperação que deveria respeitar rigorosamente as normas da propriedade intelectual.

Por trás dos discursos, das práticas e das formas de indução à internacionalização, se revelam os papéis a serem exercidos pelas universidades nas condições do desenvolvimento capitalista brasileiro. Eis por que isso redunda num fetichismo: sem poder revelar a natureza do processo de internacionalização como ampliação da subordinação nacional, se produz um discurso que o identifica como avanço, algo sempre desejável e próprio da "natureza" da universidade e da produção do conhecimento. No Brasil, a bem-sucedida operacionalização da avaliação CAPES dos programas de pós-graduação (note-se: dos programas e não da ciência brasileira) tornou-se até um modelo de exportação (BIANCHETTI; VALLE; PEREIRA, 2015). As IES internacionalizadas são consideradas de "excelência"; logo, também as mais "modernas" e avançadas, seguindo os parâmetros e as diretrizes das instituições e interesses dos países centrais. ${ }^{12}$ Os rankings internacionais nada mais fazem do que estimular esse processo de mimetização, criando também a ilusão de que a distância entre as universidades periféricas e a dos países centrais se deve apenas à conquista de "posições".

No longo processo de "modernização" da educação superior brasileira, iniciado com as reformas de 1968 e ampliado com o neoliberalismo, aquele padrão no qual a univer-

12 A Lei n. 13.005/2014, que aprovou o Plano Nacional de Educação (2014-2024), instituiu um conjunto de metas e estratégias assentado na lógica de expandir essas áreas ditas de "excelência" nas universidades. O intuito declarado é o de ampliar a "competitividade" do conhecimento nelas produzido. Sobre as estratégias do PNE (2014-2024) para a educação superior, ver Lima (2015) e Minto (2017). 
sidade podia se compatibilizar com um projeto de afirmação nacional, em razão do qual elementos como gratuidade, laicidade, financiamento estatal estratégico e autonomia, não eram simples adornos, mas necessidades, torna-se cada vez mais inviável. As pressões políticas para reforma desse nível e de suas instituições, no neoliberalismo, tornam-se mecanismos de viabilização de um duplo expediente: por um lado, reorganizar suas atividades-fim (ensino, pesquisa e extensão) para o atendimento da agenda formativa e da produção de conhecimentos prioritários para os setores dominantes na economia global, abandonando os problemas nacionais; por outro lado, viabilizá-lo como atividade mercantil, mediante o fortalecimento de um setor empresarial de venda de serviços educacionais. Leher (2010, p. 45) denominou esse processo de "capitalismo acadêmico periférico".

O contexto histórico em que se intensifica a expansão do capitalismo acadêmico é o da crise global do modo de produção capitalista, com concentradas repercussões sobre a periferia do sistema. O que está em jogo é o interesse dos capitais mais poderosos, momento em que um conjunto de instrumentos tem sido acionado para que o Estado minimize as suas funções públicas, o que se materializa na forma de um amplo retrocesso social e constitucional (como na EC n. $95^{13}$ e na reforma trabalhista, bem como, nas pressões pela reforma da previdência). Como já observara Harvey (2012, p. 87), esse tipo de ataque que afronta conquistas históricas, produtos de lutas sociais conduzidas por parte da classe trabalhadora, exige que o Estado potencialize sua dimensão coercitiva, redundando no aumento das tensões sociais. São acionadas, sobretudo, estratégias de criminalização da pobreza e, de modo geral, das formas de manifestação dos conflitos sociais, explicitando um Estado que, assim, se fortalece para proteger os interesses das corporações. Difícil não lembrar da antiga, mas em nada ultrapassada, formulação de Marx e Engels n'O Manifesto Comunista: “[O] poder executivo do Estado moderno não passa de um comitê para gerenciar os assuntos comuns de toda a burguesia" (MARX; ENGELS, 1996, p. 12).

Numa síntese de todo esse movimento que reforça a heteronomia, pode-se apontar algumas consequências para as instituições universitárias: o reforço da heterogeneidade e as muitas divisões existentes entre as universidades e, também, dentro delas. Às IES de "excelência" é reservada a função de prestar serviços estratégicos para empresas que não dispõem de departamentos de $\mathrm{P} \& \mathrm{D}$ (ou não querem embuti-los em seus custos de produção, ampliando os lucros), a exemplo da adequação de pacotes tecnológicos em departamentos especializados das universidades ou fundações privadas (LEHER, 2010, p. 21-22). Desde o início dos anos 2000, com o chamado "Livro Branco" (2002) e, posteriormente, com a "Lei de Inovação Tecnológica" (Lei n. 10.973, de 02/12/2004) e o atual "Marco legal da ciência e tecnologia e inovação" (Lei n. 13.243, de 11/01/16, regulamentada pelo Decreto n. 9.283, de 07/02/2018), não à toa, a inovação vem sendo alçada à condição de princípio orientador de grande parte da política científica no país. Por sua vez, às IES “massificadas", em sua grande maioria terceirizadas para a iniciativa privada, cabe o atendimento das demandas

13 Na Câmara dos Deputados, a mesma proposta tramitou e foi aprovada sem modificações como PEC 241/2016; no Senado, tornou-se a PEC 55 e, após sua aprovação em duas votações, converteu-se na Emenda Constitucional n. 95/2016. 
crescentes por acesso ao nível superior, oferecendo ensino a baixo custo e, com isso, também reproduzindo, no âmbito da escolarização superior, as desigualdades já existentes nos planos social, econômico, político e cultural.

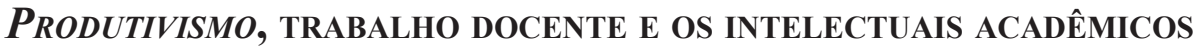

Tendo sido observador privilegiado das transformações a que a universidade brasileira foi constrangida durante o período ditatorial, Florestan Fernandes já havia tratado, nos anos 1970, de um fenômeno que muito nos interessa neste artigo: seus estudos identificaram que, num contexto de repressão (social, cultural e política), assim como de sufocamento financeiro da universidade, a instituição e seus sujeitos tendiam a internalizar - e, progressivamente, naturalizar - posicionamentos que os dispunham privilegiadamente na elite intelectual daquela sociedade capitalista dependente e periférica. Tratava-se de uma possibilidade, inclusive, material (de ganhos monetários), para além do "prestígio" acadêmico e intelectual. Pesquisas mais vinculadas aos interesses dominantes, portanto, afastadas de reivindicações populares e problemas sociais mais abrangentes, por exemplo, funcionavam como uma espécie de porta de entrada nesse universo. Criou-se uma tendência de isolamento que, segundo o autor, gerava uma espécie de "torre de marfim" cuja função era acomodar esses intelectuais às expectativas de certos papéis sociais e aos "controles societários externos" (FERNANDES, 1977, p. 125).

Para analisar as formas de manter/reproduzir a heteronomia da universidade, no período mais recente, é inevitável dar destaque para o chamado produtivismo acadêmico. Esse termo não é utilizado, aqui, para se referir a um mero quantitativismo, ou apenas às pressões por ampliar a publicação de artigos acadêmicos. Tratamos dele como uma forma de construção das condições objetivas e subjetivas ${ }^{14}$ pelas quais a universidade se adapta a um novo padrão em que o fundo público e os recursos humanos controlados pelas instituições vão sendo canalizados, em largas porções, para fins privados (nacionais e internacionais).

A agenda produtivista também se dissemina sob o manto de certa noção de inevitabilidade: a) de um lado, como se fosse uma demanda técnica, objetiva, expressa pelo recorrente apelo ao produzir mais para obter mais, ou no mostrar serviço e dar retorno à sociedade; b) de outro lado, ela é essencialmente subjetiva: aos poucos vai diluindo a memória de como foi a universidade antes do produtivismo, gerando algo como um estado de perplexidade geral que, muitas vezes, se torna motivo de lamentação, mas nem sempre de combate e resistência. As novas gerações de docentes que adentraram as instituições universitárias nos últimos anos, em boa medida, já foram formadas por essa agenda. Assumem para si padrões mais competitivos de organização do trabalho docente, podendo até ver com certa naturalidade as dificuldades daqueles/as colegas que não se adéquam a esses mesmos padrões (SGUISSARDI; SILVA JÚNIOR, 2009, p. 220-222).

14 Sobre as várias dimensões do produtivismo, bem como, das formas de resistência a ele, sugerimos a leitura do dossiê publicado pela Revista Adusp (ADUSP, 2017). 
Poderia se afirmar, ainda, que a resignação dos intelectuais acadêmicos é um dos principais produtos do produtivismo, haja vista que, à instituição de controles cada vez mais rígidos e à intensificação do trabalho, soma-se a baixa perspectiva de legitimação do trabalho acadêmico. Isso ocorre porque uma das características do produtivismo é a de gerar "produtos" efêmeros, que se tornam rapidamente obsoletos. ${ }^{15} \mathrm{~A}$ universidade e os programas de pós-graduação tornam-se ambientes insalubres, desmobilizadores, de formas de solidariedade menos presentes, quase sempre potencializando formas - despolitizadas? ${ }^{16}$ - de competitividade e individualismo. Como estudos já têm demonstrado, o adoecimento é outra consequência comum. ${ }^{17}$

Deve-se registrar que em contextos como o que está sendo aqui apresentado, também emergem formas de resistência. Algumas delas, porém, dificilmente poderiam ser caracterizadas como alternativas efetivas. Referimo-nos a duas delas, especialmente: 1) as críticas que assumem que o problema do produtivismo reside, sobretudo, na chamada indução quantitativista das políticas de avaliação. Em geral, estas se associam a um mote simplista - o contrário do produtivismo seria não produzir nada, o improdutivismo - de modo que a crítica ao conteúdo das pesquisas hoje dominantes (pois também mais favorecidas pelos recursos disponíveis), fica praticamente anulada, não opondo resistência ao tipo de "produto" que é gerado nessa lógica; 2) as posições favoráveis a um produtivismo "com relevância social". O limite dessa pretensa oposição, que supõe ser inevitável a cobrança por "produtividade", reside em não problematizar quais são os critérios de relevância social embutidos nas políticas que instituem o produtivismo, ou seja, as condições concretas nas quais se torna possível produzir e disseminar o conhecimento na sociedade contemporânea.

\title{
Autonomia ADMinistrada - A UNIVERSIDAde CONSTRANGIDA AO CURTO PRAZO
}

Leher (2003, p. 17) associa os processos de expansão do ensino superior, da pós-graduação e da pesquisa, no âmbito da chamada "modernização conservadora" da ditadura, como elemento essencial para compreender o que ainda conecta a universidade brasileira com o seu passado:

\begin{abstract}
No escopo desse processo de "modernização conservadora", parte da comunidade científica se associou ao Governo Militar, ocupando postos no aparato de fomento à C\&T e, gradativamente, passando a definir as áreas prioritárias [...], em consonância com os organismos internacionais e com os interesses econômicos e estratégicos da ditadura militar. É nossa hipótese de que aqui foram criadas as bases sobre as quais hoje pode florescer a universidade operacional.
\end{abstract}

15 Godoi e Xavier (2012, p. 459) se referem aos artigos produzidos nessa febre produtivista de junk papers (artigos inúteis, numa tradução livre).

16 Um caso emblemático desse tipo de postura pode ser visto em Herculano-Houzel (2016).

17 Um estudo amplo sobre essas temáticas, incluindo a questão da subjetividade do trabalhador docente e seu estado de saúde, pode ser encontrado em Sguissardi e Silva Júnior (2009); ver também Godoi e Xavier (2012). Sobre os impactos nos estudantes de pós-graduação, ver Oliveira (2017). 
Seria um grave erro teórico supor que essas reformas resultantes dos acordos com o Banco Mundial incidiram unilateralmente na universidade como se fosse um processo "de fora" para "dentro". Não é possível promover um corte de essência entre a política educacional do governo militar e as atuais políticas, apesar de suas significativas diferenças. A consideração da durabilidade das políticas e das práticas vigentes na instituição universitária é imprescindível para uma análise corretamente objetiva das transformações em curso nestas instituições. O ponto de interseção em que passado e presente coexistem, tensionando o presente, inclui os objetivos econômicos do desenvolvimento C\&T de ontem e de hoje. Um dos elementos que concorre para esta permanência são os pesquisadores que ontem encaminharam o projeto de modernização conservadora e hoje estão comprometidos com o projeto de mercantilização da universidade, nos termos da política governamental (LEHER, 2003, p. 17).

Resguardadas as muitas diferenças de contexto e de dimensão da pós-graduação no Brasil contemporâneo, e igualmente evitando arroubos anacrônicos, não é impreciso dizer que o sistema de avaliação CAPES, na forma como foi instituído a partir da segunda metade dos anos 1990, vem conseguindo implementar uma reorganização das atividades-fim das universidades públicas que intensificam aquela tendência aberta com a ditadura. Essa reorganização foi uma das responsáveis por instituir aquilo que Chauí chamou de organização administrada, e que também poderíamos estender: autonomia administrada. Como indicamos no item anterior, ela submete a intelectualidade acadêmica a regras de convívio e de controle que induzem processos de acomodação, afetando a produção científica e gerando uma tendência de pacificação nas instituições. A consolidação dessas práticas avaliativas, cada vez mais atreladas (e servindo de parâmetro) ao financiamento das atividades-fim da universidade, sobretudo da pesquisa, estabelece condições bastante restritas para o exercício de qualquer autonomia, haja vista que instituem como "natural" aquilo que para ela seria "estranho": a lógica, o tempo, a relação quantidade-qualidade, características da sociedade mercantil. No final da década de 1970, Tragtenberg (2004, p. 18) denominara esse desvio de finalidade como delinquência acadêmica, situação na qual os controles burocráticos tomavam o lugar da criação do conhecimento e que os fins formativos se subsumiam nos meios e técnicas, que se tornavam a nova finalidade.

A atual educação superior pública brasileira, portanto, é produto de um longo período de acomodação dessa lógica. Ela institui e consolida certas identidades, bem como, busca neutralizar as forças em contrário. Como afirmam Godoi e Xavier (2012), tem-se um "ciclo insano" que passa a ser aceito como inevitável (pois normalizado):

A proliferação de papers científicos sob a lógica do empilhamento, não da criação do conhecimento e da relevância social, transformou a publicação desse subproduto em um fim em si mesmo. A ênfase, nos últimos dez anos, foi deslocada da pesquisa e produção de conhecimento para a produção e publicação de artigos. Chamamos ao resultado desse deslocamento de Parnasianismo Acadêmico (GODOI; XAVIER, 2012, p. 458). 
Usando, ainda, a metáfora do empilhamento, os autores apontam para as consequências nefastas desse ciclo:

\begin{abstract}
Isso envolve tratar de temas consagrados, sempre ancorados na mainstream vigente e, preferencialmente, de forma objetiva. A replicação superficial do conhecimento é o caminho comum, em que novas proposições são evitadas, e nada é contestado, tampouco criado. O formato é preciso, métricas são observadas como em um soneto, e um roteiro é trilhado cumprindo todas as recomendações estéticas do periódico (GODOI; XAVIER, 2012, p. 459).
\end{abstract}

O estudo de Bianchetti, Valle e Pereira (2015, p. 85-89) igualmente constata que o produtivismo gera uma quantidade excessiva de artigos acadêmicos disponíveis, muitos deles sobre temáticas repetitivas. Para os autores, órgãos reguladores da pesquisa, como a CAPES e o CNPq, mudam de caráter com suas práticas e induções: seus mecanismos de mediação tornam-se entes instituintes, isto é, ao invés de meios para a divulgação e apresentação pública de certas atividades, tornam-se o próprio fim da atividade de pesquisa. Nesse processo, o currículo Lattes, repositório das atividades realizadas, se "reifica" (IDEM, p. 91), como se se tornasse uma materialização da pesquisa. ${ }^{18}$

O corolário disso que alguns chamam de ciclo insano, que Tragtenberg denominou de delinquência acadêmica ou, ainda, que Florestan Fernandes tratara como torre de marfim, é o abandono de qualquer perspectiva ético-política que se expresse num tripé ensino, pesquisa e extensão efetivamente orientado para fins públicos, ou seja, voltado para o atendimento das questões vitais para as maiorias. Fomenta-se uma política caracterizada por práticas e processos decisórios que operam, cada vez mais, no plano do imediato. O curto prazo é a dimensão temporal dominante: da atualização sistemática do Currículo Lattes, dos editais de auxílio à pesquisa e, até, da avaliação dos programas de pós-graduação pela Capes em períodos de três ou quatro anos. Se, por um lado, esse curtoprazismo em nada responde aos desafios de um conhecimento científico socialmente orientado, por outro lado, a hegemonia que valoriza a circulação do conhecimento em "periódicos qualificados", também neutraliza parte substantiva do potencial crítico e político do conhecimento produzido, haja vista que os tempos médios para a publicação nas revistas mais qualificadas tendem a ser cada vez mais longos, impedindo, na prática, que assuntos da "ordem do dia" sejam abordados do ponto de vista científico, por exemplo, em casos de intervenção na construção de políticas públicas.

A lógica da organização e da forma do trabalho (a produção acadêmica) se sobrepõe à lógica do conteúdo concreto deste trabalho (o conhecimento científico e as atividades-fim da universidade), realizando de modo avassalador aquilo que no final da década de 1960, no calor da hora dos debates sobre a "reforma universitária" e sob forte repressão da ditadura, Florestan Fernandes denominara de "supressão do radicalismo intelectual" (FERNANDES, 1975, p. 32). A capacidade que a intelectualidade universitária tem de elaborar e pensar sobre o futuro se enfraquece severamente:

18 Para uma visão diferente desses processos, ver Wood Jr. (2016). 
A institucionalização dos intelectuais, transformados agora em funcionários dedicados a preencher requisitos predeterminados para não serem excluídos ou em experts consagrados para responder a demandas sociais, mas principalmente políticas, administrativas e econômicas, gera a necessidade de criação de uma cultura na academia que tanto dissolve a definição do que se entende por intelectual quanto restringe a abrangência de sua práxis (BIANCHETTI; VALLE; PEREIRA, 2015, p. 88).

Em suma, a universidade contemporânea vem se caracterizando por um modo de organização que tende a inviabilizar a produção autônoma do conhecimento, um padrão que Chauí (2001) denominou, no contexto da reforma do Estado e da educação dos anos 1990, de "universidade operacional".

\section{Autonomia como ideologia conservadora}

Um dos objetivos deste estudo, ao propor a análise da autonomia universitária como um produto possível de relações sociais e educacionais numa sociedade de classes periférica como a brasileira, era o de fugir do lugar-comum que caracterizou parte significativa do discurso acadêmico nas últimas décadas. Em nosso modo de ver, a autonomia não é uma mera condição que, simplesmente, se perde em função das medidas de um ou de outro governo. Compreendê-la, de modo radical, exige que as suas determinações mais gerais - isto é, o campo de disputas real e concreto das políticas - sejam enfrentadas, o que grande parte da produção acadêmica não se propõe mais a fazer.

A universidade não é uma instituição que, por suas finalidades e tradições, está imune às determinações da sociabilidade contemporânea do capital. Tampouco ocorrem, numa sociedade capitalista periférica em tempos de crise estrutural, mudanças rigorosamente idênticas àquelas das universidades dos países centrais, apesar da insistente cobrança oficial para que mimetizemos seus padrões. $\mathrm{O}$ declínio da fase histórica em que a dinâmica capitalista podia ser mantida sob certos controles, domesticando, por assim dizer, a sua lógica destrutiva, também encerrou um período em que certos pactos e contratos sociais entre o capital e o trabalho implicavam limites para a destrutibilidade aceitável para viabilizar e expandir a acumulação. O neoliberalismo, ideologia representativa da fase contemporânea de expansão e acumulação do capital, vem colocando essas convenções por terra. É o momento em que a defesa da autonomia da universidade pode ganhar, também, um sentido ideológico conservador.

Naturalmente, estamos nos referindo ao sentido hegemônico que redefiniu a noção de autonomia nas políticas educacionais, lapidada em meio ao conflito de posições distintas e antagônicas sobre a universidade no contexto das reformas neoliberais. Se, nos anos 1980, a autonomia reaparecia como uma demanda política essencial, capaz de unir propostas bastante distintas em torno de bandeiras comuns, da década de 1990 em diante as divergências se tornam cada vez mais evidentes, como que "autorizando" que concepções conservadoras de autonomia busquem hegemonia. 
Um exemplo de conservadorismo ideológico é o discurso recorrente de que as instituições e as políticas para a universidade são feitas "pelos pares". Esta é uma forma de ocultar as posições antagônicas que convivem dentro das instituições, como se as práticas e atividades universitárias não as expressassem. O efeito desse discurso é nefasto, pois, se por um lado ele explica pouco da situação das universidades, por outro, ele cria um campo arbitrário de determinações, no qual os indivíduos e suas ações supostamente poderiam "fazer a diferença". A conclusão é deveras simplista: se os pares é que fazem, o fazem porque querem e estão autorizados pelos próprios pares. Em outros termos: seria um produto da autonomia, mas não de outras determinações fundamentais.

Outra forma de ideologização da autonomia é mais complexa e envolve algo que perdura no tempo e na memória. Trata-se daquele efeito de sedimentação produzido pela insistência em tratar da autonomia como uma condição inerente à universidade. Ao se reivindicar uma universidade-espaço da plena e integral realização humana, do cultivo do saber puro, da cultura clássica e universal, promove-se uma espécie de adesão (saudosista, porque sempre referenciada num passado imaginário), e legitimação das posturas conservadoras em relação à universidade. Com isso, não se revela que, na sua existência concreta, aquela não só pode conviver como, também, ser parceira estratégica da barbárie cotidiana do modo de produção capitalista. ${ }^{19}$

Outros usos ideológicos comuns têm sido aqueles que reduzem a autonomia a uma acepção tecnicista, de gestão financeira ou, ainda, a uma visão sobre o que seria a "missão" da universidade. Um caso emblemático da última é a expressão quarta missão da universidade, usada para se referir ao que seria um processo histórico inevitável, com ares de "evolução" das funções e papéis dessas instituições, materializado no processo de internacionalização, do qual já tratamos. O uso do termo "missão" reforça o sentido ideológico que a autonomia ganha ao se confrontar com a internacionalização, colocando um véu sobre as reais mudanças em jogo, que são tomadas como um dado: o que muda é o mundo, mas a universidade permanece tendo como "missão" se adequar a ele. ${ }^{20}$

Discursos positivos em relação às políticas para o ensino superior implementadas durante os governos petistas, apoiados na interpretação de que teria ocorrido uma ruptura entre os mandatos FHC (1995-2002) e Lula/Dilma (2003-2016), ${ }^{21}$ foram recorrentes em certos espaços acadêmicos, em movimentos organizados ligados ao campo educacional e, também, entre educadores e educadoras. Mas, eles coincidiam com uma situação nova

19 Para uma reflexão sobre as formas de como o direito (a forma jurídica) oculta as relações sociais concretas, estabelecendo um repertório de "demandas" que, efetivamente, afastam o campo educacional de uma situação nova e potencialmente transformadora, recomendamos a leitura de Catini (2017).

20 Sobre isso, ver Santos e Almeida Filho (2012), autores que estão na "linha de frente" dessa defesa, repetindo velhos chavões de organismos como Banco Mundial e Unesco. Sobre a internacionalização, afirmam: "Exercida nos moldes que cada universidade define, na prossecução de objetivos que só a ela compete estabelecer, a internacionalização será mais um fator que garante a diversidade do sistema. Ela é portanto, simultaneamente, uma manifestação e um vector da autonomia, já que, por um lado, não existiria sem ela e, por outro, a reformula, a concretiza e a impõe" (2012, p. 59).

21 Para uma introdução a algumas das ideias que fomentam as controvérsias em torno da temática ruptura-continuidade, sugerimos a leitura de Davies (2016) e Gentili e Oliveira (2013). 
para a autonomia no caso das universidades? Embora a retórica da ruptura se remeta a conquistas que produzem efeitos contraditórios, como o crescimento da população de baixa renda matriculada no nível superior, e de sua relevância política, no sentido de manter vivas certas perspectivas de organização e luta, ela merece uma análise crítica pelos efeitos negativos que produz. Primeiro, porque tendia a silenciar sobre problemas de fundo, como o do declínio do projeto de desenvolvimento em bases nacionais e autônomas, bem como, a mercantilização do ensino; segundo, porque fomentou a flexibilização da noção de "público", distanciando-a de elementos como gratuidade e financiamento estatal, por conseguinte autorizando e legitimando a mediação privada na oferta do ensino, sobretudo por instituições empresariais (MINTO, 2017, p. 36-37). ${ }^{22}$ Do ponto de vista da autonomia, sem dúvida, foi uma política regressiva.

Em todos esses casos, trata-se de narrativas que tergiversam sobre problemas reais que se intensificam nas universidades, como o avanço do privatismo, dos processos individualizantes, de concorrência entre pares e de consequente quebra de solidariedade, entre outras evidências de que essas instituições também são parte do processo vivo e dinâmico que se impõe às sociedades comandadas pelo capital.

\section{CONSIDERAÇÕES FINAIS: LUTAR POR QUAL AUTONOMIA?}

Num cenário que tende a agudizar o caráter heterônomo da universidade - de esgotamento das políticas de financiamento estatal destinadas à realização de uma universidade (uma educação superior) ampla, massiva e orientada para propósitos igualmente universalizantes; de impactos financeiros dramáticos que as medidas recentes do governo brasileiro, como a aprovação da EC n. 95/2016; de fortalecimento das corporações privadas do ensino superior, por meio do maior fluxo para aquele nível ${ }^{23}$ com o "novo FIES", somados aos efeitos deletérios da regulamentação do "Marco da ciência, tecnologia e inovação" - a favor de qual autonomia ainda é possível lutar?

A despeito desse contexto desfavorável, a luta organizada por uma autonomia universitária, concreta e substantiva, permanece viva. Mas, devemos ressaltar novamente: autonomia não é uma condição que se perdeu ou apenas um princípio jurídico; tampouco é apenas um modelo que não se implementou corretamente ou que se inviabilizou historicamente. A busca por autonomia diz respeito ao futuro do país e da universidade; implica posicionar-se sobre as formas pelas quais ela se construiu como instituição, sobre a história que a precedeu; implica encontrar as formas possíveis de construção de uma instituição universitária adequada a outros propósitos sociais, culturais e econômicos. Defender a au-

22 A ênfase desse discurso recaiu, principalmente, sobre as transferências de recursos públicos para o setor privado via PROUNI e FIES.

23 A Lei n. 13.415/2017, que reformou o ensino médio, abre brechas para isso. Ao "flexibilizar" as formas de saída dessa etapa, criando um sistema de créditos que poderão ser validados no nível superior em instituições "parceiras", pode vir a beneficiar o setor privado, que teria a chance de estabelecer relações comerciais mais próximas com as redes de educação básica, criando uma espécie de reserva de mercado. 
tonomia da universidade no século XXI, de muitas maneiras, é defender a transformação dessa instituição e, portanto, das condições sociais nas quais ela se produz e se torna possível. Por ser uma transformação que não é apenas $d a$ universidade, mas de toda a sociedade vigente, de suas formas de organização e reprodução, é no terreno concreto das lutas sociais e coletivas que se pode travar essa batalha. Sem esquecer que, por se tratar de interesses em disputa, via de regra antagônicos, parte da comunidade universitária estará em seu favor, enquanto outra parte a negará, o mesmo ocorrendo na sociedade em geral.

Por isso, neste artigo, quando nos referimos a esse objetivo geral, estamos tratando: do atendimento das demandas cruciais para as maiorias formadas, sobretudo, pela classe trabalhadora brasileira; de um ensino, pesquisa e extensão capazes de enfrentar problemas vitais; da gratuidade plena e indiscriminada do ensino superior estatal; da disseminação do conhecimento, destituindo-o de suas matrizes produtivistas e concentradoras; da democratização do acesso e o fomento à políticas de permanência ativa nas instituições; da superação da tendência diferenciadora do ensino, que não raro produz ensino a baixo custo para as camadas mais pobres da população, enquanto reserva o melhor do ensino superior para os que "podem pagar" (tendência que cresce, cada vez mais, também nas IES públicas). A ilusão de que possa haver uma "comunidade acadêmica" alinhada com esses objetivos comuns não passa de um instrumento ideológico conservador. Buscar a efetiva autonomia da universidade também implica não aceitar que as forças conservadoras deem ao termo a acepção que lhes convém.

\section{REFERÊNCIAS}

ADUSP. Dossiê "produtivismo acadêmico": (ainda é) tempo de reagir. Revista Adusp, São Paulo, n. 60, mai. 2017.

AMARAL, Nelson C. Com a PEC 241/55 (EC 95) haverá prioridade para cumprir as metas do PNE (2014-2024)? Revista Brasileira de Educação, Rio de Janeiro, v. 22, n. 71, 2017, p. $1-25$.

ANDRADE, Rodrigo O. Distúrbios na academia. Pesquisa Fapesp, ed. 262, dez. 2017.

BANCO MUNDIAL. La enseñanza superior: las lecciones derivadas de la experiencia. Washington D.C.: BIRD/Banco Mundial, 1995.

BENTO, Jorge O. Abalos na torre de marfim: descaminhos e desatinos da Universidade. Campinas, SP: Editora da Unicamp, 2016.

BIANCHETTI, L.; VALLE, I.; PEREIRA, G. O fim dos intelectuais acadêmicos?: induções da CAPES e desafios às associações científicas. Campinas: Autores Associados, 2015. 
BLOCH, Marc. Apologia da história, ou, O ofício do historiador. Rio de Janeiro: Jorge Zahar Ed., 2001.

CATINI, Carolina de R. Privatização da educação e gestão da barbárie: crítica da forma do direito. São Paulo: Edições Lado Esquerdo, 2017.

CHARLE, C.; VERGER, J. História das universidades. São Paulo: Ed. Unesp, 1996.

CHAUÍ, Marilena. Escritos sobre a universidade. São Paulo: Ed. Unesp, 2001.

DAVIES, Nicholas. A política educacional nos governos do PT: continuidades ou descontinuidades em relação aos do PSDB? Revista HISTEDBR On-line, Campinas, n. 67, p. 39-52, mar. 2016.

DELORS, J. et al. Educação: um tesouro a descobrir (Relatório para a UNESCO da Comissão Internacional sobre educação para o século XXI), 5. ed. São Paulo: Cortez, 2001.

FÁVERO, Maria de L. A. Autonomia universitária: desafios histórico-políticos. Universidade e Sociedade, Brasília, DF: ANDES, ano VII, n. 12, fev. 1997, p. 09-12.

. Autonomia universitária: necessidades e desafios. Cadernos CEDES, Campinas, SP, n. 22, 1988, p. 7-16.

FERNANDES, Florestan. Circuito fechado: quatro ensaios sobre o "poder institucional". São Paulo: HUCITEC, 1979.

. Universidade brasileira: reforma ou revolução? São Paulo: Alfa-Omega, 1975.

FETIZÓN, Beatriz. A universidade e sua alma endemoninhada. São Paulo: FEUSP, 2012. Série Estudos \& Documentos, v. 45.

GENTILI, P.; OLIVEIRA, D. A procura da igualdade: dez anos de política educacional no Brasil. In: SADER, Emir (Org.). 10 anos de governos pós-neoliberais no Brasil: Lula e Dilma. São Paulo, SP: Boitempo; Rio de Janeiro, RJ: FLACSO Brasil, 2013.

GODOI, C. K.; XAVIER, W. G. O produtivismo e suas anomalias. Cad. EBAPE.BR, Rio de Janeiro/RJ, v. 10, n. 2, opinião 1, p. 456-465, jun. 2012.

HARVEY, David. O neoliberalismo: história e implicações. 3. ed. São Paulo: Edições Loyola, 2012.

HERCULANO-HOUZEL, Suzana. Neurocientista defende universidades geridas como empresas: 'É preciso demitir quem não produz'. BBC Brasil, 30/05/2016. Disponível em: $<$ http://www.bbc.com/portuguese/brasil-36365112>. Acesso em: 5 dez. 2016. 
LEHER, Roberto. Capitalismo dependiente y educación: propuestas para la problemática universitaria. In: . (Compilador). Por una reforma radical de las universidades latinoamericanas. 1. ed. Rosario: Homo Sapiens Ediciones, 2010, p. 19-93.

. Projetos e modelos de autonomia e privatização das universidades públicas. Revista da ADUEL, Londrina, v. 1, n. 1, set. 2003m p. 7-20.

LIMA, Kátia. Plano Nacional de Educação 2014-2024: nova fase do privatismo e da certificação em larga escala. Universidade e Sociedade, Brasília, n. 55, fev. 2015.

MANCEBO, Deise. Autonomia universitária: reformas propostas e resistência cultural. Universidade e Sociedade, Brasília, ano VIII, n. 15, p. 51-59, fev. 1998.

MARX, K.; ENGELS, F. O manifesto comunista [trad. Maria L. Como]. Rio de Janeiro: Paz e Terra, 1996.

MINTO, Lalo W. A educação da "miséria": particularidade capitalista e educação superior no Brasil. São Paulo: Outras Expressões, 2014.

. A educação superior entre o público e o privado: do PNE à PEC 241/2016. In: SILVA Jr. et al. (Org.). Política de educação superior brasileira: apontamentos e perspectivas. Belo Horizonte, MG: Fino Traço/Faculdade de Educação da UnB, 2017.

MINTO, L.; RODRIGUES, F.; GONZALEZ, J. Notas sobre "Escola Sem partido". Dossiê Escola Sem Partido, Blog Marxismo 21, out. 2016. Disponível em: $<$ http://marxismo21. org/escola-sem-partido/>. Acesso em: 5 dez. 2016.

OURIQUES, Nildo. Ciência e pós-graduação na universidade brasileira. In: RAMPINELLI, W.; OURIQUES, N. (Org.). Crítica à razão acadêmica: reflexão sobre a universidade contemporânea. Florianópolis: Insular, 2011, p. 73-107.

PACHUKANIS, Evgeny B. Teoria geral do direito e marxismo. São Paulo: Editora Acadêmica, 1988.

RANIERI, Nina. Autonomia universitária: as universidades públicas e a Constituição Federal de 1988. São Paulo: Editora da Universidade de São Paulo, 1994.

SANTOS, F. S.; ALMEIDA FILHO, N. de. A quarta missão da universidade: internacionalização universitária na sociedade do conhecimento. Coimbra: Imprensa da Universidade de Coimbra; Brasília, DF: Editora da UnB, 2012.

SGUISSARDI; V. SILVA JÚNIOR, J. Trabalho intensificado nas federais: pós-graduação e produtivismo acadêmico. São Paulo: Xamã, 2009. 
SOUZA, Paulo R. Governador: escolha sua universidade. Qual universidade? In: ARAÚJO, Braz (Org.). A crise da USP. São Paulo: Brasiliense, 1980, p. 17-19.

TRAGTENBERG, Maurício. Sobre educação, política e sindicalismo. 3. ed. rev. São Paulo: Editora Unesp, 2004.

WOOD JR., Thomaz. A academia e seus comportamentos patológicos. Carta Capital, 01/12/2016. Disponível em: http://www.cartacapital.com.br/revista/929/a-academia-e-seus-comportamentos-patologicos. Acesso em: 5 dez. 2016.

\section{Dados do AUtor:}

\section{LALO WATANABE MINTO}

Graduado em Ciências Econômicas pela Universidade Estadual Paulista (2001),

Mestre (2005) e Doutor (2011) em Educação pela Universidade Estadual de Campinas. Professor da Faculdade de Educação da Unicamp e Coordenador do Grupo de Estudos e Pesquisas Educação e Crítica Social (GEPECS). Contato: lalo@unicamp.br

Submetido em: 20-3-2018

Aceito em: 4-10-2018 